\title{
Research on the Training Mode of Applied Talents in Computer Specialty Jointly Built By Schools and Enterprises
}

\author{
Lunbin $\mathrm{Li}^{1}$, Shiying Wang ${ }^{2}$ and Dan $\mathrm{Su}^{3}$ \\ ${ }^{1}$ Heihe University, Heihe 164300, China; \\ ${ }^{2}$ Heihe University, Heihe 164300, China; \\ ${ }^{3}$ Heihe University, Heihe 164300, China.
}

Keywords: Computer specialty; personnel training; curriculum design; application type.

\begin{abstract}
Aiming at the problems existing in the process of training applied talents of computer specialty; this paper puts forward the mode of school-enterprise cooperation education. This paper probes into the concrete measures of the employment-oriented talent training mode of computer specialty from the aspects of training mode, talent training goal, curriculum design and teaching management. Practice shows that school-enterprise cooperative education can help students develop good professional habits. They have mastered a set of Engineering methods, such as system analysis, system design, test and maintenance, and their practical innovation ability has been enhanced, and the quality of personnel training has been greatly improved.
\end{abstract}

\section{Introduction}

With the rapid development of computer technology and information industry, computers are widely used in various industries. The demand for computer professionals is increasing. There is a large gap of talents, but there is a contradiction between the employment difficulties of computer graduates [1]. The main reason is not that the quantity is too large or the quality is too poor, but that the pertinence of meeting the social needs is not clear enough. Strengthening the communication and interaction among students, schools and employers is the key to win three win [2]. As an educational mode, school enterprise cooperation education integrates theoretical study and practical activities better [3]. It breaks through the single mode of personnel training, makes schools and enterprises, teachers and enterprises, students and enterprises to establish a wide range of contacts, and in the process of extensive exchanges with enterprises to acquire knowledge, cultivate students' ability, improve overall quality [4]. For Newly-built Local Undergraduate Colleges and universities, computer specialty is applied. Graduates mainly go to enterprises. By establishing links with enterprises, they can understand and study the needs of enterprises for talents, so as to adjust the training plan, establish the training mode of talents, and construct a new curriculum system.

\section{Training Mode}

With the rapid development of computer technology and information industry, computers are widely used in various industries. The demand for computer professionals is increasing. There is a large gap of talents, but there is a contradiction between the employment difficulties of computer graduates. The main reason is not that the quantity is too large or the quality is too poor, but that the pertinence of meeting the social needs is not clear enough. Strengthening the communication and interaction among students, schools and employers is the key to win three win. As an educational mode, school enterprise cooperation education integrates theoretical study and practical activities better. It breaks through the single mode of personnel training, makes schools and enterprises, teachers and enterprises, students and enterprises to establish a wide range of contacts, and in the process of extensive exchanges with enterprises to acquire knowledge, cultivate students' ability, improve overall quality. For Newly-built Local Undergraduate Colleges and universities, computer specialty is applied. Graduates mainly go to enterprises. By establishing links with enterprises, they can understand and study the needs of enterprises for talents, so as to adjust the training plan, establish the training mode of talents, and construct a new curriculum system. 


\section{Personnel Training Objectives}

\subsection{Employment target.}

Java development engineer, Java Web development engineer, implementation engineer or test engineer.

\subsection{Capability objectives.}

To train students to independently complete the analysis, design, implementation, test, deployment and maintenance of a small and medium-sized enterprise business system, have strong learning ability, analytical ability and problem solving ability, and develop good professional habits and comprehensive qualities [5].

\subsection{Training concept.}

Close to the needs of enterprises, and develop training programs based on occupation and position. In terms of training content, it is guided by such key points as "Deepening the training of basic knowledge vigorously; Increasing the training of Applied Technology substantially; Running through the daily training of soft skills; Actual training of projects required by enterprise standards". In terms of training methods, CDIO engineering practice teaching concept should be fully implemented: student-centered instead of syllabus or teacher-centered; a large number of case-based teaching instead of theoretical teaching; project-driven instead of curriculum-driven; fish-teaching instead of fish-teaching; teacher-student interaction and role exchange instead of simple teaching and listening Class. Close to the enterprise: quasi-employee work, study and life; strongly emphasize engineering practice, ensure that at least one third of the school hours are used for enterprise training and internship. The training practice adopts the enterprise 5R education idea, namely: the real working environment, the real enterprise project case, the real project manager, the real work pressure, the real employment opportunity.

\subsection{Personnel training mode.}

Case driven: there are two levels. At the level of a single course, a course is divided into several small cases, each case demonstrates a knowledge point; after all the cases are completed, all the knowledge structure of the course will be completed. At the level of a series of courses, each course completes one stage or part of a large project case, and all the courses in the series together complete the whole large case [6]. For example, Web development foundation, database theory and application, Java EE development technology, software testing technology and other courses are integrated into "Software Engineering Series Courses". Each course completes UI design, database design, coding development and testing of a large case (e.g. mobile tourism social system).

Centralized and continuous teaching: public courses and basic courses are still decentralized according to the unified arrangement of colleges and universities, but the specialized courses, characteristic courses and training links, which are responsible for by enterprises, are taught in a centralized and continuous way. For example, it will be divided into 48 classes in one semester and 6 days to complete. Practice shows that the application oriented curriculum can achieve the best training effect by centralization and continuity.

Learn to do: For beginners, use the way of "master leads in the door", that is, "learn to do", to help beginners enter this field. In some cases, teachers need to lead students from shallow to deep, so that students can eliminate psychological barriers and gain interest and motivation through practice.

Learning by doing: For the students who have a certain foundation, the way of "learning by doing" is adopted. The students take the needs and problems to actively learn and solve problems. When problems arise and they do not know how to solve them, the project manager gives advice and tells the solution. When students encounter technical barriers that they can not cross, project managers can help students solve technical problems in time, so that students can continue to move forward and ultimately let students learn practical application technology in the process of doing projects and grow up quickly.

Combination of Learning and Doing: For outstanding people, we should adopt "Combination of Learning and Doing". Firstly, teachers should point out higher development goals for them. Then, students can learn while doing through their own efforts, and finally make achievements in specific fields.

Real Engineering Practice: Select outstanding students to participate in real business projects, with strict customer requirements and strict quality control, training future industry "elite". 


\section{Curriculum Plan}

\subsection{Curriculum provision.}

Compulsory courses and compulsory courses: Higher Mathematics 1, C Language Programming, Professional Introduction*, Higher Mathematics 2, Probability Theory and Mathematical Statistics, Linear Algebra, Java Language Programming, Data Structure, Composition Principle and Assembly Language, Java Language Course Design Training*, Database Principle and Application, Operating System, Design Computer Network, Software Engineering, Enterprise Application Comprehensive Project Training*, Modern Web Front-end Course Design Training*, Java Open Source Framework Course Design Training*, C Program Course Design, Computer Assembly and Maintenance, Discrete Mathematics, Algorithmic Design and Application, Web UI Foundation*, LAN Formation and Management, Compiling Principle, ASP.NET Program Programming, Java Open Source Framework Programming*, Modern Web Front-end Development Technology*, Data Structure Course Design*, Java SE Course Design Training*, Java SE Core Development Technology*, Java EE Programming*, Java EE Course Design Training*, Android Operating System*, Large Enterprise Project Architecture Design*, etc. The courses in the superscript * are sent to schools by companies, or at corporate bases.

\subsection{Curriculum design training.}

Course design and training requires students to design and develop a small application program independently under the guidance of the training project manager, and submit demonstration reviews one by one, and prepare course design reports. The curriculum design training project is provided by enterprises. The training results consist of the presentation of the demonstration results, the results of the course design report and the usual grades.

\subsection{Comprehensive project training.}

Comprehensive project training requires students to independently complete the whole process of analysis, design, development, testing, deployment and submission of a medium-sized software system under the guidance of the training project manager, in accordance with the methods and specifications of software engineering, and with the team as the unit.

Enterprises provide 3 to 5 large and medium-sized project station cases for each project group selection. For example: logistics distribution system, fixed assets investment management system, science and technology project approval management system, tourism social networking website system, online education platform, self-Media website system, sensor data processing and control system, etc.

Develop projects in strict accordance with software engineering specifications, project managers explain project requirements, and teams analyze and validate requirements. According to the needs of the project and the technical foundation of the students, the project manager or assistant of the enterprise will carry out certain technical and project process training. Each project team makes project prototypes respectively, and the project manager reviews the prototype of each group. Each project group designs database, application architecture, object and business process separately. The project manager reviews the design of each group system. Coding and unit testing, the project manager or assistant checks the code of each student. The modules were integrated, the team was launched, the test version was released, the teams were cross tested, and the bug was repaired. Each group demonstrates the project of this group, the project manager and the group leader scored each group item separately, and selected the excellent project group and the outstanding individual.

The assessment methods of training performance are team score accounting for $50 \%$, project leader score accounting for $30 \%$ and project manager score accounting for $20 \%$. Among them, team score is $20 \%$ for prototype design, $20 \%$ for system design and $60 \%$ for project submission. The first two results are given by the training project manager, and the project submission results are graded by all project team leaders and training project managers respectively, and then the average is obtained. The team leader's score is given by the team leader according to the performance of the team members. Project manager's score: the project manager gives the result and daily performance according to the student's code review. 


\subsection{Professional and Technical Courses.}

All the professional courses in charge of enterprises adopt the case-based teaching method, and all courses should be assessed by written examination or demonstration reply.

\subsection{Vocational quality curriculum.}

In addition to technical training, enterprises will introduce the following soft skills, professional quality, career planning training in the whole training process: senior leadership lectures, outreach activities, documents, Email, PPT, career planning, resume, written examination, interview guidance, labor law and probation guidance.

\subsection{Graduation design.}

Enterprises provide graduation design topic selection, assignment, opening report, graduation design project guidance, mid-term inspection, paper review, Defense Review and other services. The topic selection and opening of the graduation project will start in the middle of the sixth term. Enterprises require students to complete all the development work of graduation projects through the "graduation project training" course during the training period in the enterprise base, and take it as the mid-term examination of graduation projects. Students can only recommend internship through the mid-term examination of the graduation design. The students completed the graduation project in the seventh, eighth semester and wrote graduation design papers. In the eighth semester, I returned to the enterprise training base to take part in the graduation design reply.

\section{Teaching Management}

\subsection{Management mechanism.}

The two sides set up a joint working group on professional teaching management, which is fully responsible for the implementation of professional co construction. Job responsibilities include the design and revision of personnel training plans, the compilation and verification of curriculum/training syllabus, the training process and quality supervision, students' daily learning, assessment management, and emergency coordination.

Personnel composition: group leader: deputy dean of College teaching; director of enterprise training technology; unified interface person of daily affairs: teaching secretary of College (or corresponding personnel); supervisor of enterprise training operation. Other members: College counselors, relevant teachers; enterprise training project manager/lecturer, teaching head teacher, quality commissioner.

\subsection{Document submission.}

Enterprises submit the following documents to colleges and universities: the joint professional training plan agreed upon and confirmed by both sides; the curriculum/training outline for enterprises at the beginning of each semester; the courseware and students' scores after each course/training for enterprises; and the monthly report for enterprises during the training period is submitted to colleges. After the completion of the training, the training report is submitted to the college.

\subsection{Graduation design.}

Enterprises are responsible for: topic selection, graduation design task book; topic opening guidance and topic report (technical) review; graduation design project development guidance; mid-term inspection and evaluation; graduation thesis (technical) review; provide defense evaluation teachers to participate in graduation defense.

Colleges and universities are responsible for: graduation design task book review; topic opening report (format aspect) review; graduation thesis (format aspect) review; provide defense evaluation teachers to participate in graduation defense.

\subsection{Quality supervision.}

The curriculum implemented by the school is in compliance with the relevant school system. In the course implemented in the enterprise base, the "Quality Commissioner" of the enterprise is responsible for supervising teaching discipline, collecting students' feedback, receiving and resolving students' complaints. 


\section{Conclusion}

After several years of exploration and practice, the talent training program of school-enterprise cooperation is guided by social demand, market demand and employment demand, optimizes the curriculum system, enlarges the proportion of practical courses and applied elective courses, and ensures the coordinated development of knowledge, ability and quality. Graduates of computer specialty trained through School-enterprise cooperative education mode are generally welcomed by the society and employers. Practice has proved that school-enterprise cooperative education has trained students' ideological and moral quality, mastered a set of engineering methods such as system analysis, system design, test and maintenance, and enhanced their practical innovation ability. In the process of contacting customers, their language and written expression ability, social public relations ability, comprehensive judgment ability, adaptability and other aspects have been exercised, and the quality of personnel training has been greatly improved.

\section{Acknowledgment}

Higher Education Teaching Reform Project in Heilongjiang Province, Project Number: SJGY0207, Project Name: Research on Training Model of Applied Talents of Computer Major in Newly-built Local Undergraduate Colleges.

\section{References}

[1]. Yang Yuting, to build a market-oriented training model for high-quality application-oriented computer talents in independent colleges, Hangzhou: Computer Age, 2018. (In Chinese)

[2]. Zhao Zheng, computer application talents training mode exploration, Shijiazhuang: Industry and Technology Forum, 2018. (In Chinese)

[3]. Su Dan, Exploration and Practice of Training Applied Computer Talents in Newly-built Local Undergraduate Colleges, Beijing: Electronic Production, 2014. (In Chinese)

[4]. Wang Yongqiang, Research on the Training Model of Computer Professionals in Local Undergraduate Colleges with School-Enterprise Cooperation. Fuzhou: Fujian Computer, 2014. (In Chinese)

[5]. Chen Zuocong, Research on the Training Model of Applied Talents of Computer Specialty under the Background of Transformation, Beijing: Computer Education, 2018. (In Chinese)

[6]. Fan Jingbo, Exploration and Practice of Computer Professional Training Model in Local Undergraduate Colleges, Shanghai: Microcomputer Applications, 2015. (In Chinese) 